\title{
THE EFFECT OF DEINKING AND BINDER TYPE ON INKJET PRINT QUALITY
}

\author{
Arif Ozcan ${ }^{1}$ (D), Emine Arman Kandirmaz ${ }^{1}$ (D), Omer Bunyamin Zelzele ${ }^{2}$ \\ ${ }^{1}$ Marmara University, School of Applied Sciences, Printing Technologies, Istanbul, Turkey \\ ${ }^{2}$ Marmara University, Vocational School of Technical Sciences, Printing and Publishing \\ Technologies, Istanbul, Turkey
}

\begin{abstract}
In the printing industry, as in all other industries, efficient use of resources, sustainable production and economics are among the most important issues. The increasing use and purpose of printed products, the increasing consumer demands and the development of technology also increase the demand for paper products. Paper and cardboard materials in line with the increasing consumer demand to give better printing characteristics are implemented in a number of operations. These processes are sizing, coating, and calendering. The recycling and re-use of paper and cartons that have been treated on the surface may also differ from those that have not been treated on the surface. For this purpose, test prints were made on paper coated with cationic starch and PVOH binders and precipitated calcium carbonate (PCC) pigment before and after recycling with Inkjet printing system, which is widely used today. The effect of both recycling and binder type on the quality of the resulting prints has been studied. The colour value, dot gain, whiteness and yellowness of the prints were made using X-Rite exact spectrophotometer. The gloss measurements were carried out with BYK-Gardner glossmeter. In addition, images of coated papers were analyzed with scanning electron microscope SEM. As a result, it was determined that there was a negative change in the colour and whiteness of the papers after recycling, but the resulting papers had a good printability value when examined in terms of printability. It has also been concluded that the PVOH binder has a more positive impact on printability.
\end{abstract}

Keywords: Inkjet, Printability, PVOH, Recycle, Starch.

\section{INTRODUCTION}

With the industrial and technological developments and the increase in consumption in recent years, all industrial enterprises have begun a search of different alternatives in supplying the required raw materials. One of the foremost alternatives among these efforts is the efficient use of raw material resources without waste, and another alternative is the importance of recycling. The most important basic raw materials used in the printing industry are paper and cardboard. Despite the increase in digital publishing, the need for paper does not decrease, and they still remain the most important raw materials due to their use in different areas. In parallel with the technological developments in the printing industry, productivity has increased and waste rates have decreased. In addition, the importance of recycled paper and cardboard in raw material supply has increased day by day. This is because in the recycling process, it is easier to collect paper and cardboard and re-use them as raw materials compared to many other waste materials and paper and cardboard can be recycled 5-6 times. Paper recycling involves the collection of used or waste paper for reprocessing for reuse. According to CEPI statistics, the rate of recycled fiber in paper production was 53.1\% in 2018 and 54.6\% in 2019, and the rate of paper recycling was $72 \%$ in 2019 with an increase of $1 \%$ compared to the previous year (Confederation of European Paper Industries, 2019). In addition, it is known that more than $60 \%$ of the paper consumed in the USA is recycled (Du et al, 2016) and the demand for recycled fiber has increased over the years (Dorris et al, 2011). In terms of the environment and the economy, paper recycling reduces the need for raw materials (cutting less trees), the use of energy resources (water, electricity, etc.), raw material costs, and creates new business opportunities in the recycling sector.

One of the most important factors affecting print quality is the treatments applied to paper and cardboard, during or after production, which are widely used as printing substrates. During or after paper and cardboard production, a number of surface treatments such as sizing, coating and calendering are performed in order to have better workability and printability (Ozcan and Kandirmaz, 2020). Sizing is the process of filling the pores by bonding the surface of the paper with a binding agent, and coating is the process of coating paper and cardboard surfaces with mixed formulas obtained with pigment, binder and some additional substances. Calendering is a type of compression process done to increase the brightness and smoothness of the paper surface (Ozcan and Tutak, 2020). Today, calcium carbonate derivatives, pigments such as kaolin, titanium dioxide and silica are widely used in paper coatings, and 
starch types, some cellulose types, PVA, PVOH and latex types are used as binders. Binders allow for better adhesion of pigments in the coating formulation to the paper surface and fills the pores caused by the fibers. The functions of binders can be briefly listed as good adhesion properties, water retention, and improving optical and mechanical properties. After coating, the paper exhibits better printability properties.

Deinking is the process of separating printing inks and other foreign matter from paper fibers in order to reuse waste paper. The ratio of ink and other foreign matter to be removed varies between 0.5 and $2 \%$. These substances other than ink are usually adhesives and fillers. Deinking agents are usually fatty acids, nonionic surfactants, or mixtures of both; but these materials can be modified with different chemicals to achieve better results (Tutak, 2017). Recycled fibers are essential for paper production and environmental protection (Toppinen et al, 2017). There are two basic stages: pulping of waste papers and removal of ink and other foreign matter. Flotation and washing are the two most commonly used methods. In recent years, the flotation method has been preferred over washing because of higher efficiency while consuming less water (İmamoğlu and Peşman, 2012). The performance of the deinking process may vary depending on the printing technique used, printing conditions, type of ink, and type of printing substrate (Bolanča and Bolanča, 2004; Tsatsis et al, 2017).

Flotation is the process of attaching hydrophobic ink and foreign particles to air bubbles and the removal of these air bubbles by sending them to the foamy surface formed on the suspension surface. Flotation is a much more complex separation process than it seems. Factors affecting the performance of flotation are ink particle quantity, size, shape, density, surface chemistry, air bubble type, number, size, surface chemistry and structure, mixing type, intensity, duration, and process conditions. These process conditions are determined by the waste paper type, ink amount and type, amount of inorganic matter, fiber characteristics, $\mathrm{pH}$, and chemical environment (Mavros and Matis, 2009).

Inkjet printing is a widely used digital printing technology where printing takes place by ejecting ink from a nozzle via piezoelectric motion in a closed chamber (Figure 1). Inkjet ink consists of a solute dissolved or otherwise dispersed in solvent (Tekin et al, 2008). The ink inside the continuously moving print head ejects a fixed amount of ink out of the nozzle due to the shock effect by electrical voltage changes (Lim et al, 2008). Printing is performed as these droplet-shaped inks are transferred to various printing substrates such as paper, cardboard, fabric, metal, ceramic, glass, etc. As with other digital technologies, there is no need for a printing plate and the ink is transferred directly to the printing substrate. The popularity of inkjet printing has grown significantly over the past decade, and this trend will continue in the future due to faster printing, better print quality, on-demand printing capabilities and exceptional features of inkjet printing (Du et al, 2016). In addition, the use of inkjet printing has also increased over the years due to environmental and health concerns (Aksoy et al, 2006).

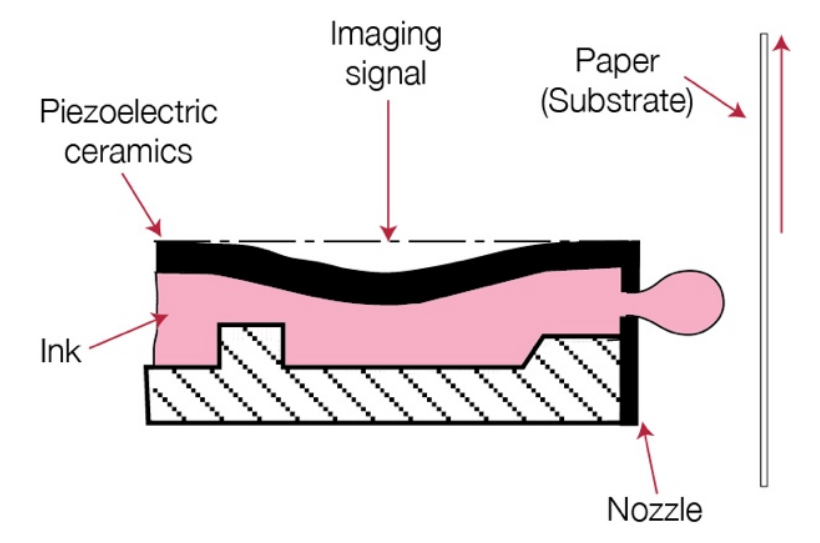

Figure 1: Drop on demand piezo inkjet printing (Kipphan, 2001)

For this purpose, two different coating formulations will be prepared in this study using PCC pigment with $\mathrm{PVOH}$ and cationic starch binders and these formulations will be coated on base paper. The coated papers will be printed with the inkjet printing system, whose usage has increased in recent years. After printing, deinking will be performed according to the Ingede method 11. Inkjet printing will be performed again on the hand-sheets obtained after the deinking process. By doing so, firstly, the effect of binder type on the printability of paper coatings and secondly, the surface properties of these coatings after deinking will be examined. 


\section{METHODS}

To examine the effects of different binders, coating formulations were prepared by using calcium carbonate pigment precipitated with polyvinyl alcohol (PVOH) and cationic starch binders (Table 1). PCC and water were mixed for $25 \mathrm{~min}$ and polyvinyl alcohol and cationic starch were cooked for $25 \mathrm{~min}$ at $30^{\circ} \mathrm{C}$ with $45 \%$ solid content in a cold water with three blade mixer at $1200 \mathrm{rpm}$ speed and were dispersed with lab dissolver. The $\mathrm{pH}$ of coating was adjusted to 8.5. The viscosities of the coatings were being measured at room temperature using a Brookfield viscometer, \#4 spindle, at $100 \mathrm{rpm}$. The papers were conditioned for 48 hours before coating. Coating was performed with a bar coater (model K303 Multicoater, RK Print) to $21.0 \times 29.7-\mathrm{cm}$ base sheets with the speed of $2 \mathrm{~m} / \mathrm{min}$ automatically. Coatings were allowed to dry for $24 \mathrm{~h}$ at $20^{\circ} \mathrm{C}$ and $65 \%$ relative humidity (RH). A laboratory-type paper coating device was used in the presence of Mayer rod number 2. Optical and physical properties of base paper and coated papers are given in Table 2. The inkjet printer used for this study was Epson L365. Its printing technology is drop-on-demand and uses piezo print heads and the ink is pigment based. Ingede Method 11:2018 was used for recycling process with the standard chemicals (Figure 2).

Technidyne Brightimeter Micro S-5 was used to measure brightness according to ISO 2470-2:2008. The colour properties of the coated papers and deinked hand-sheets were determined using CIEL*a*b* colour values. The X-Rite eXact hand-held spectrophotometer was used to measure $\mathrm{CIEL}^{*} \mathrm{a}^{*} \mathrm{~b}^{*}$ according to ISO 5631-2:2008. The spectrophotometer was used in a spectral range of 400-700nm, using a D50 light source, a 2-degree observer, polarization filters open and 0/45 degrees of geometry. Gloss measurements were made with BYK-Gardner GmbH glossmeter according to ISO 8254-1:2009 $75^{\circ}$ geometry.

Table 1: Paper coating formulations used in the study

\begin{tabular}{|l|l|l|l|}
\hline & $\begin{array}{l}\text { Solid } \\
\text { content }\end{array}$ & $\begin{array}{l}\text { F1 } \\
\text { (Coated with } \\
\text { PVOH) }\end{array}$ & $\begin{array}{l}\text { F2 } \\
\text { (Coated with } \\
\text { Cationic Starch) }\end{array}$ \\
\hline Ingredients & & \multicolumn{2}{|l|}{ Dry Parts Added (gram) } \\
\hline $\begin{array}{l}\text { Precipitated Calcium } \\
\text { Carbonate } \mathrm{CaCO}_{3}(\mathrm{PCC})\end{array}$ & $65 \%$ & 100 & 100 \\
\hline Polyvinyl Alcohol (PVOH) & $45 \%$ & 10 & - \\
\hline Cationic Starch & $45 \%$ & - & 10 \\
\hline Dispersant & $40 \%$ & 0.2 & 0.2 \\
\hline Thickener & $30 \%$ & 0.8 & 0.8 \\
\hline
\end{tabular}

Table 2: Physical and optical properties of base paper and coated papers

\begin{tabular}{|c|c|c|c|c|c|}
\hline & & Standard & Base Paper & F1 & $\mathrm{F} 2$ \\
\hline ISO & ness (\%) & ISO 2470-2:2008 & 84.30 & 90.75 & 90.05 \\
\hline Opa & & ISO $2471: 2008$ & 88.66 & 89.12 & 90.08 \\
\hline Wei & & ISO 536:2012 & 51.31 & 57.45 & 57.76 \\
\hline Rou & Bendtsen (ml/min) & ISO 8791-3:2017 & 206.34 & 230.87 & 235.55 \\
\hline Thic & & ISO 534:2005 & 78 & 94 & 98 \\
\hline Glos & & ISO 8254-1:2009 & 5.7 & 15 & 16.9 \\
\hline \multirow{3}{*}{\multicolumn{2}{|c|}{$\mathrm{ClE}$}} & \multirow{3}{*}{ ISO 5631-2:2008 } & 94.08 & 96.88 & 96.90 \\
\hline & & & 0.08 & 0.14 & 0.15 \\
\hline & & & 1.68 & 1.17 & 0.98 \\
\hline $\mathrm{CIE}$ & hess & ISO $11475: 2017$ & 76.06 & 79.66 & 76.75 \\
\hline
\end{tabular}




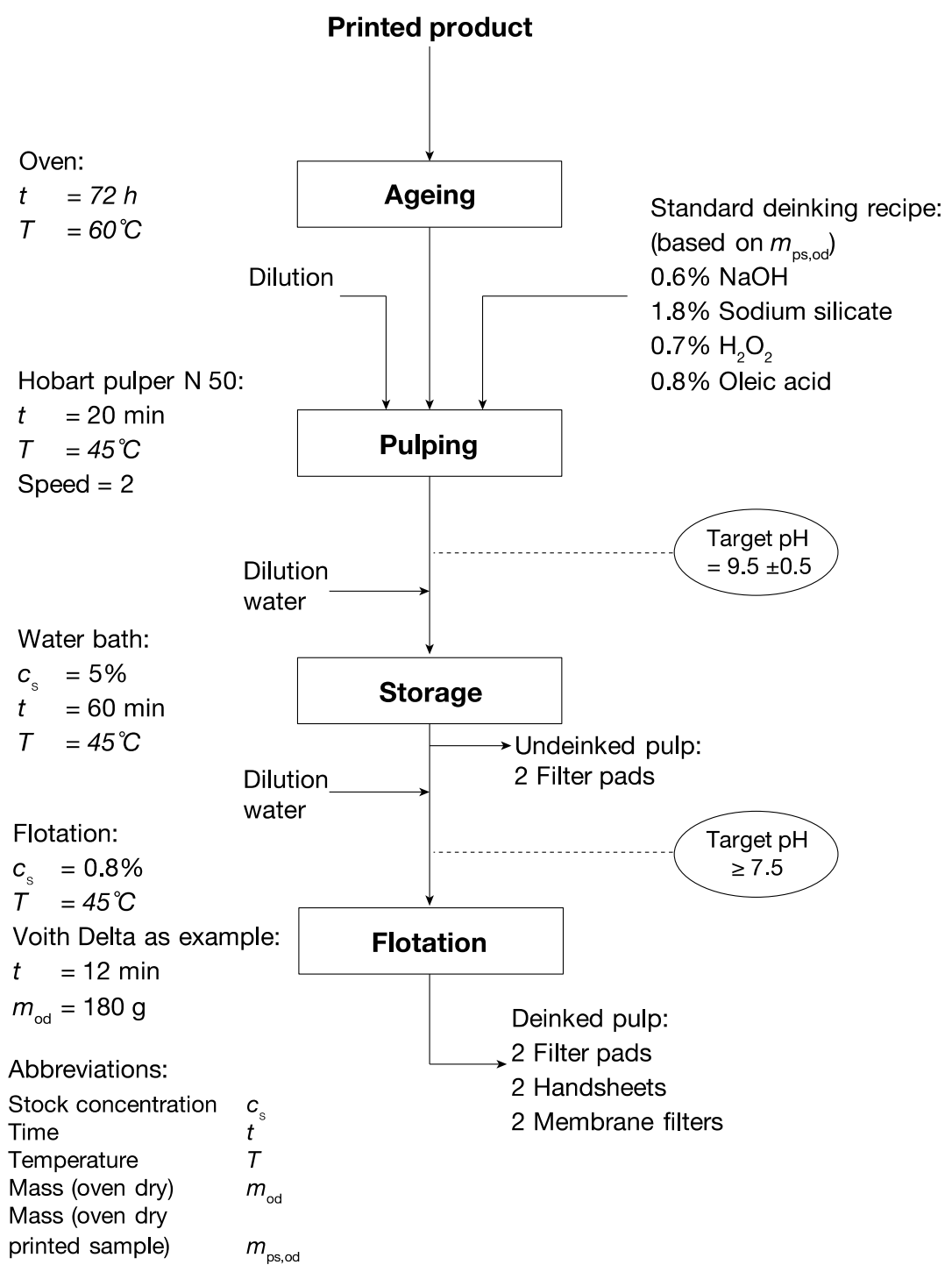

Figure 2: Procedure for testing deinkability with standard deinking recipe (INGEDE Method 11, 2018)

\section{RESULTS}

The paper deinking was completed, deinked hand-sheets and filter-pads were measured to compare their whiteness values according to ISO 11475:2017 and ISO 5631-2:2008 standard was used for their CIEL*a*b* values (Table 3). The highest whiteness value was obtained in coatings made with PVOH (79.66). The whiteness value of the coating made with cationic starch was higher compared to the base paper. In the hand-sheets obtained after the deinking process, the highest whiteness value was obtained in the coating made with PVOH (62.97), followed by the coating made with cationic starch. The lowest whiteness value in hand-sheets was also obtained in base paper.

Table 3: CIE L*a*b* colour and whiteness values of coated papers and deinked hand-sheets

\begin{tabular}{|c|l|l|l|l|l|l|}
\hline & $\begin{array}{l}\text { Base } \\
\text { Paper }\end{array}$ & $\begin{array}{l}\text { Base paper } \\
\text { deinked } \\
\text { hand-sheet }\end{array}$ & F1 & $\begin{array}{l}\text { F1 deinked } \\
\text { hand-sheet }\end{array}$ & F2 & $\begin{array}{l}\text { F2 deinked } \\
\text { hand-sheet }\end{array}$ \\
\hline CIE $\quad \begin{array}{l}\text { L* } \\
\text { a* } \\
\text { b* }\end{array}$ & 94.08 & 87.15 & 96.88 & 89.13 & 96.90 & 86.18 \\
\cline { 2 - 8 } & 0.08 & -0.34 & 0.14 & -2.10 & 0.15 & -2.93 \\
\cline { 2 - 8 } & 1.68 & 4.36 & 1.17 & 1.87 & 0.98 & 1.79 \\
\hline CIE Whiteness & 76.06 & 46.07 & 79.66 & 62.97 & 76.75 & 57.58 \\
\hline
\end{tabular}


Colour differences of inkjet printing made on base paper, coated papers and hand-sheets obtained after deinking are given in Table 4. When the table is examined, there are visible colour differences in the coated papers in the $\Delta \mathrm{E}$ colour difference measurements made with reference to the base paper inkjet printing results. This difference indicates the improvement in printability for coated papers. Colour differences in inkjet printing on hand-sheets after deinking are at acceptable levels. These results show that all hand-sheets are very similar to each other after deinking, and ink particles and coating materials are removed from the environment during the flotation process.

Table 4: $\Delta E$ colour differences between printed base paper, coated papers and deinked hand-sheets

\begin{tabular}{|c|c|c|c|c|}
\hline & $\Delta \mathrm{E}_{00} \mathrm{C}$ & $\Delta \mathrm{E}_{00} \mathrm{M}$ & \multicolumn{4}{|c|}{$\Delta \mathrm{E}_{00} \mathrm{Y}$} & $\Delta \mathrm{E}_{00 \mathrm{~K}}$ \\
\hline Base Paper & \multicolumn{4}{|c|}{ Reference } \\
\hline F1 & 0.72 & 5.67 & 4.10 & 4.49 \\
\hline F2 & 2.66 & 9.34 & 7.06 & 7.04 \\
\hline Base Paper Deinked & \multicolumn{5}{|c|}{ Reference } \\
\hline F1 Deinked & 1.67 & 0.86 & 1.67 & 0.65 \\
\hline F2 Deinked & 1.86 & 0.69 & 1.78 & 1.33 \\
\hline
\end{tabular}

Comparison of ISO brightness values of base paper, coated papers and hand-sheets obtained after deinking according to ISO 2470-2:2008 are shown in Figure 3. When the brightness values are examined, it can be seen that the brightness values in both coatings are higher compared to the base paper. The brightness value of coating made with $\mathrm{PVOH}$ (F1) was obtained as 90.05, which was higher than that of the coating made with cationic starch (F2), obtained as 90.75 .

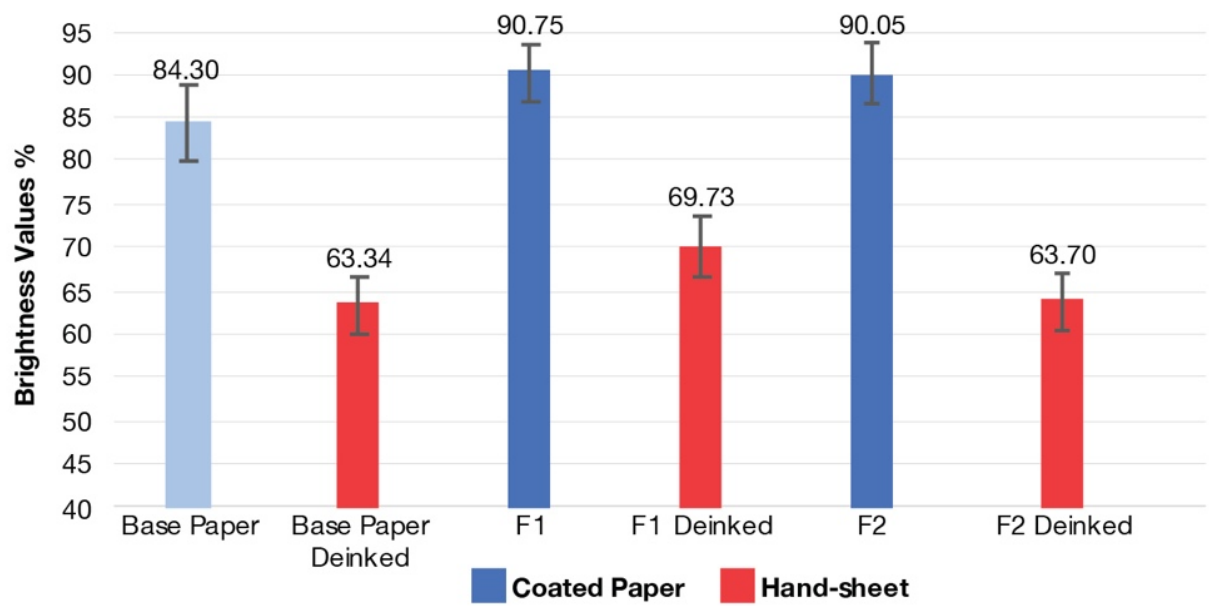

Figure 3: Brightness values of coated papers and hand-sheet papers

The paper deinking was completed, base paper, coated papers and deinked hand-sheets were measured to compare their gloss values according to ISO 8254-1:2009 (Figure 4). When the gloss values are examined, it can be seen that the gloss values of both coatings increased compared to base paper. The gloss value of the coating made with cationic starch (16.9) was higher than the gloss value of the coating made with PVOH (15.0). 


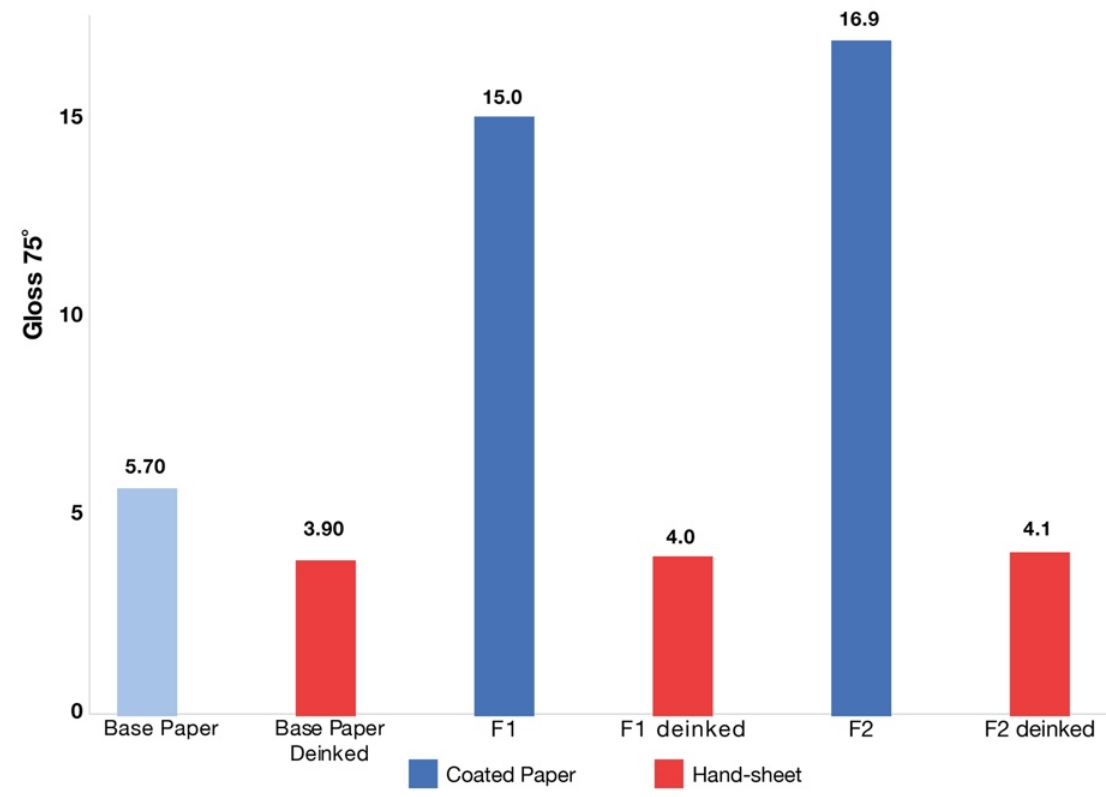

Figure 4: Gloss values of coated papers and hand-sheet papers

The X-Ray Diffraction patterns of PCC doped PVOH hybrid film and PCC doped cationic starch hybrid film are shown in Figure 5. When the PCC doped PVOH film is examined, three peaks between $2 \theta=24.11^{\circ}$, $36.14^{\circ}$ and $39.58^{\circ}$ are proves the crystalline structure of calcium carbonate and $2 \theta=15^{\circ}$ clearly show the semicrystalline structure of PVOH. The results are supported by literature (Kisku et al, 2014; Zidan, 2003). PCC doped cationic starch film were examined, the above-mentioned peaks of $2 \theta=24.11^{\circ}, 36.14^{\circ}$ and $39.58^{\circ}$ of calcium carbonate are clearly visible. Besides, the strong reflections of cationic starch were revealed at $2 \theta=15^{\circ}$ and $23^{\circ}$. These results are in line with the literature (Pi-Xin et al, 2009). According to the obtained results, the structure of the coatings is proven by XRD.

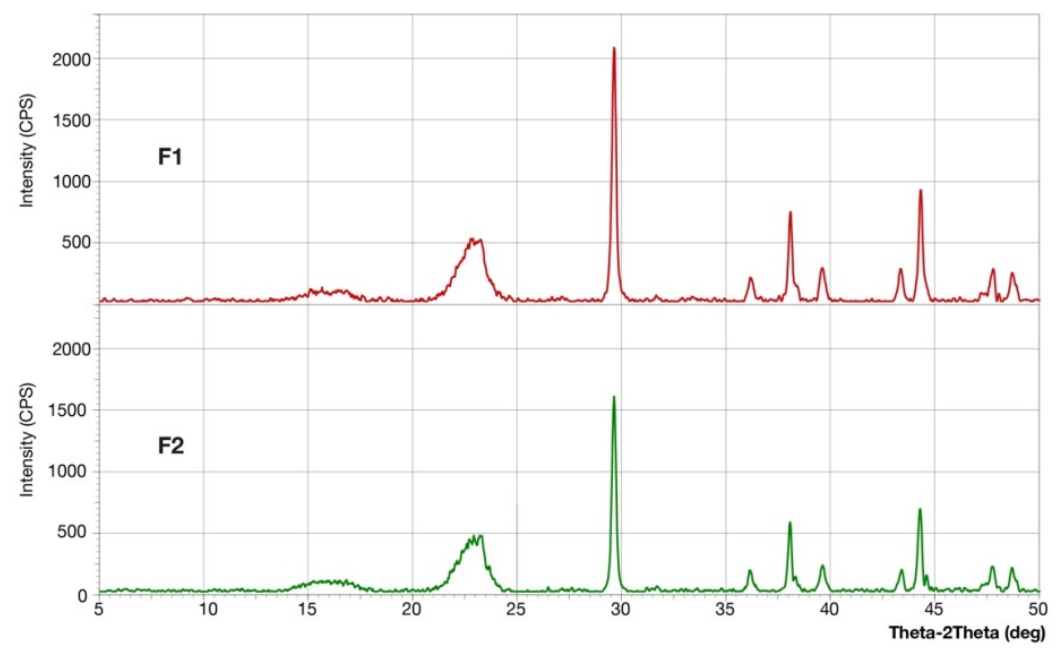

Figure 5: X-ray diffractograms of PCC doped PVOH hybrid film (F1) and PCC doped cationic starch hybrid film (F2)

The dimensions of the coatings obtained were studied using the scanning electron microscope (Figure 6). When the obtained coated papers surfaces were examined with SEM, it was determined that the surface was smooth and without cracks in both coatings. These surfaces increase the visibility of even small dots in printing and improve print quality. When the coatings are compared among themselves, the surface of the PCC-PVOH coating is smoother. Because the cationic starch polymer is a fibrous macromolecule and it is usual to create some roughness compared to $\mathrm{PVOH}$. However, this difference is not enough to affect the print quality. Both polymeric materials have provided the desired smooth surface by closing the gaps on the paper surface. 


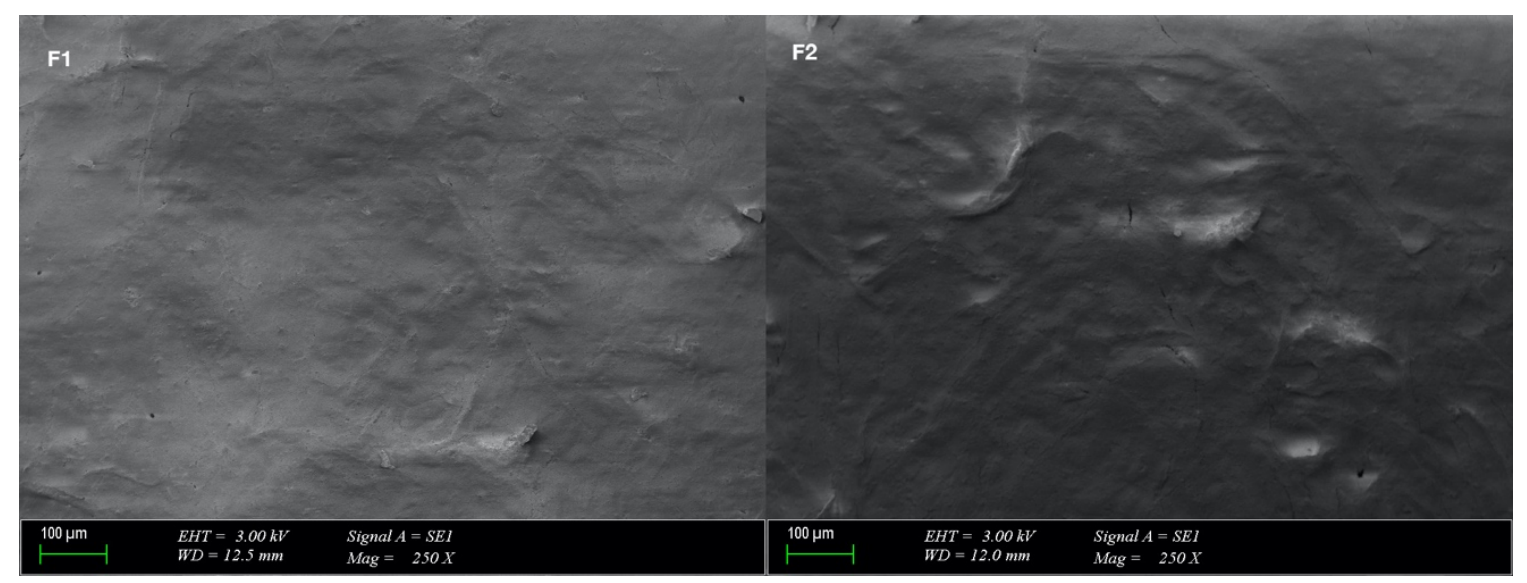

Figure 6: SEM image of the PCC-PVOH coated (F1) and PCC-cationic starch coated (F2) papers

\section{CONCLUSIONS}

Higher brightness values were obtained in coated papers. When the binders were compared, a slightly higher brightness value was obtained in the coatings made with PVOH compared to cationic starch. In hand-sheets obtained after deinking, the brightness value was also higher in coatings made with $\mathrm{PVOH}$ (Figure 3). The reason for this is that the coated papers do not prevent the ink from penetrating into the paper, thus increasing colour saturation. The higher values obtained with $\mathrm{PVOH}$ can be attributed to better movement in capillaries, thus the effect described above is exhibited more clearly. The higher brightness after deinking in coatings made with $\mathrm{PVOH}$ indicates that $\mathrm{PVOH}$ can be removed less from cellulose fibers. Higher opacity values were obtained in coatings made with cationic starch compared to coatings made with PVOH (Table 2). This is because starch is more opaque than PVOH due to its structure. This is reflected in the opacity of the coatings. Basis weight values were found to be the same. This shows that the coating amounts are set correctly. Thickness values were slightly higher in coatings made with cationic starch. This difference is due to the fact that cationic starch is denser than PVOH. Gloss values were slightly higher in coatings made with cationic starch (Figure 4). This is because PVOH moves better through capillary spaces, therefore it remains less on the surface. Starch remained on the surface more and spread the polymeric chain brightness on the surface. Whiteness values were higher in coatings made with PVOH. This is because the crystalline form of $\mathrm{PVOH}$ is white, which increased the whiteness of the paper. When the CIEL*a*b* values are examined, the results show that colour differences decrease after the deinking process, that is, the dirt remaining in the paper is removed to a large extent, bringing the colour closer to that of the reference paper. When XRD results are examined, the crystalline structure of the coating formulations can be seen clearly. SEM results show that both coatings produce a smooth, crack-free paper with better printability. In conclusion, it was determined that the type of binder affects both colour, gloss, and opacity. Cationic starch use is recommended when the emphasis is on opacity and gloss, whereas $\mathrm{PVOH}$ use is recommended when the emphasis is on brightness, whiteness, and surface roughness.

\section{REFERENCES}

[1] Aksoy, H., Yõlmaz, S., Çelik, M., Yüzbaşığlu, D., Ünal, F.: “Genotoxicity study in lymphocytes of offset printing workers", Journal of applied toxicology 26 (1), 10-15, 2006. doi: 10.1002/jat.1098.

[2] Bolanča, I., Bolanča, Z.: "Chemical and enzymatic deinking flotation of digital prints", 4th International DAAAM Conference 2004, (Industrial Engineering-Innovation As Competitive Edge for SME, Tallinn, Estonia, 2004), pages 173-176.

[3] Dorris, G., Ben, Y., Richard, M.: "Overview of flotation deinking", Progress in paper recycling 20 (1), 3-42, 2011.

[4] Du, X. T., Lee, D. T., Hsieh, J. S.: "Inkjet ink behaviors and its implication in adsorption deinking", Separation Science and Technology 51 (18), 2857-2867, 2016. doi: 10.1080/01496395.2016.1226902. 
[5] İmamoğlu, S., Peşman, E.: "Flotasyon süresinin mürekkep giderme işlemi ve hamur kalitesine etkisi", Artvin Çoruh Üniversitesi Orman Fakültesi Dergisi 13 (2), 250-269, 2012.

[6] INGEDE, International Association of the Deinking Industry: "INGEDE Method 11 - Assessment of print product recyclability - Deinkability test - ", URL:

https://www.ingede.com/ingindxe/methods/ingede-method-11-2018.pdf (last request: 2020-09-30).

[7] Kipphan, H.: "Handbook of print media: technologies and production methods", (Springer Science \& Business Media, Heidelberg, 2001).

[8] Confederation of European Paper Industries (CEPI), "Key statistics, European Pulp \& Paper Industry", URL: https://www.cepi.org/wp-content/uploads/2020/07/Final-Key-Statistics-2019.pdf (last request: 2020-09-30).

[9] Kisku, S.K., Sarkar, N., Dash, S., Swain, S.K.: "Preparation of starch/PVA/CaCO3 nanobiocomposite films: study of fire retardant, thermal resistant, gas barrier and biodegradable properties", PolymerPlastics Technology and Engineering 53 (16):1664-1670, 2014. doi:10.1080/03602559.2014.919650.

[10] Lim, J. A., Lee, W. H., Lee, H. S., Lee, J. H., Park, Y. D., Cho, K.: "Self-Organization of Ink-jet-Printed Triisopropylsilylethynyl Pentacene via Evaporation-Induced Flows in a Drying Droplet", Advanced functional materials 18 (2), 229-234, 2008. doi: 10.1002/adfm. 200700859.

[11] Mavros, P., Matis, K. A.: "Innovations in Flotation Technology", (NATO ASI Series, 2009).

[12] Ozcan, A., Arman Kandirmaz, E.: "Natural ink production and printability studies for smart food packaging", Color Research \& Application 45 (3), 495-502, 2020. doi: 10.1002/col.22488.

[13] Ozcan, A., Tutak, D.: "The effect of zeolite on inkjet coated paper surface properties and deinking", Nordic Pulp \& Paper Research Journal 35 (3), 432-439, 2020. doi: 10.1515/npprj-2020-0025.

[14] Pi-Xin, W., Xiu-Li, W., Xue, D. H., Xu, K., Tan, Y., Du, X. B., Li, W. B.: "Preparation and characterization of cationic corn starch with a high degree of substitution in dioxane-THF-water media", Carbohydrate Research 344 (7), 851-855, 2009. doi: 10.1016/j.carres.2009.02.023.

[15] Tekin, E., Smith, P. J., Schubert, U. S.: "Inkjet printing as a deposition and patterning tool for polymers and inorganic particles". Soft Matter 4 (4), 703-713, 2008. doi: 10.1039/B711984D.

[16] Toppinen, A., Pätäri, S., Tuppura, A., Jantunen, A.: "The European pulp and paper industry in transition to a bio-economy: A Delphi study", Futures 88, 1-14, 2017. doi: 10.1016/j.futures.2017.02.002.

[17] Tsatsis, D. E., Papachristos, D. K., Valta, K. A., Vlyssides, A. G., Economides, D. G.: "Enzymatic deinking for recycling of office waste paper", Journal of environmental chemical engineering 5 (2), 1744-1753, 2017. doi: 10.1016/j.jece.2017.03.007.

[18] Tutak, D.: "Modified deinking of digitally printed paper with water based inkjet ink", Cellulose Chemistry and Technology 51 (5-6), 483-488, 2017.

[19] Zidan, H.M.: "Structural properties of CrF3-and $\mathrm{MnCl}$-filled poly (vinyl alcohol) films", Journal of Applied Polymer Science 88 (5), 1115-1120, 2003. doi: 10.1002/app.12123.

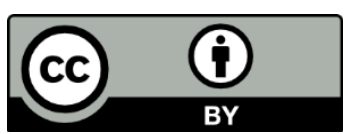

(C) 2020 Authors. Published by the University of Novi Sad, Faculty of Technical Sciences, Department of Graphic Engineering and Design. This article is an open access article distributed under the terms and conditions of the Creative Commons Attribution license 3.0 Serbia (http://creativecommons.org/licenses/by/3.0/rs/). 